\title{
Parallelized Biocatalytic Scanning Probe Lithography for the Additive Fabrication of Conjugated Polymer Structures
}

DOI:

10.1039/C8NR01283K

\section{Document Version}

Accepted author manuscript

Link to publication record in Manchester Research Explorer

\section{Citation for published version (APA):}

Hosford, J., Valles, M., Krainer, F. W., Glieder, A., \& Wong, L. S. (2018). Parallelized Biocatalytic Scanning Probe Lithography for the Additive Fabrication of Conjugated Polymer Structures. Nanoscale, 10, 7185-7193.

https://doi.org/10.1039/C8NR01283K

\section{Published in:}

Nanoscale

\section{Citing this paper}

Please note that where the full-text provided on Manchester Research Explorer is the Author Accepted Manuscript or Proof version this may differ from the final Published version. If citing, it is advised that you check and use the publisher's definitive version.

\section{General rights}

Copyright and moral rights for the publications made accessible in the Research Explorer are retained by the authors and/or other copyright owners and it is a condition of accessing publications that users recognise and abide by the legal requirements associated with these rights.

\section{Takedown policy}

If you believe that this document breaches copyright please refer to the University of Manchester's Takedown Procedures [http://man.ac.uk/04Y6Bo] or contact uml.scholarlycommunications@manchester.ac.uk providing relevant details, so we can investigate your claim.

\section{OPEN ACCESS}




\section{Parallelized Biocatalytic Scanning Probe Lithography for the Additive Fabrication of Conjugated Polymer Structures}

Joseph Hosford, ${ }^{\dagger}$ Morgane Valles, ${ }^{\dagger}$ Florian W. Krainer, ${ }^{\star}$ Anton Glieder, ${ }^{\star}$ Lu Shin Wong ${ }^{\dagger *}$

$\dagger$ Manchester Institute of Biotechnology and School of Chemistry, University of Manchester, 131 Princess Street, Manchester M1 7DN, United Kingdom.

$\ddagger$ Institute of Molecular Biotechnology, Graz University of Technology, NAWI Graz, Petersgasse 14, 8010 Graz, Austria.

* email: $\underline{\text { l.s.wong@ manchester.ac.uk }}$

\section{Abstract}

Scanning probe lithography (SPL) offers a more accessible alternative to conventional photolithography as a route to surface nanofabrication. In principle, the synthetic scope of SPL could be greatly enhanced by combining the precision of scanning probe systems with the chemoselectivity offered by biocatalysis. This report describes the development of multiplexed SPL employing probes functionalized with horseradish peroxidase, and its subsequent use for the constructive fabrication of polyaniline features on both silicon oxide and gold substrates. This polymer is of particular interest due to its potential applications in organic electronics, but its use is hindered by its poor processability, which could be circumvented by the direct in situ synthesis at the desired locations. Using parallelized arrays of probes, the lithography of polymer features over $1 \mathrm{~cm}^{2}$ areas was achieved with individual feature widths as small as $162 \pm 24 \mathrm{~nm}$. The nature of the deposited materials was confirmed by Raman spectroscopy, and it was further shown that the features could be chemically 
derivatized postlithographically by Huisgen [2+3] "click" chemistry, when propargyloxyaniline was used as the monomer in the initial lithography step.

\section{Introduction}

Scanning probe lithography (SPL) represents a family of surface nanolithography methods based on scanning probe microscopy platforms, where the probe tip is used to localize a physical or chemical manipulation of the surface. Such SPL-based methods have attracted much interest in nanoscience since they can achieve nanoscale resolution and registry, and are able to "write" any user-defined pattern, using instrumentation that is readily accessible. Indeed, the major impetus for the development of new SPL methods has been the need to address the limitations of classical "hard" lithography techniques derived from the microelectronics sector, such as the lack of flexibility for rapid design prototyping and the patterning of "soft" materials such as small organic molecules, polymers or biomolecules. ${ }^{1,2}$

In terms of physical manipulation, scanning probes have been used for the mechanical removal of material (c.f. nanoshaving and nanografting), ${ }^{3-6}$ the application of an electrical bias to induce oxidation (local anodic oxidation or local oxidation nanolithography), ${ }^{7,8}$ and heating of the probes to perform thermally induced effects (thermochemical nanolithography). ${ }^{9}$

The use of scanning probes for the local delivery of materials has also been demonstrated. In dip-pen nanolithography (DPN), an atomic force microscopy (AFM) probe tip directs the local deposition of "ink" molecules onto a surface by diffusion of the molecules from the probe to the surface. ${ }^{1,2,10}$ Scanning probes with microfluidic channels ("nanopipettes" and "nano-fountain pens") for the delivery of inks to surfaces have also been reported. ${ }^{11}$ This group of methods is particularly interesting as they are examples of "additive" 
or "constructive" fabrication, since the surface features are formed by the deposition of material, rather than the removal or ablation of materials ("subtractive" or "destructive") that typify conventional hard lithography.

In principle, an attractive approach to additive nanofabrication is to use scanning probes bearing a catalyst to directly synthesize materials in situ. Such an approach would combine the precision of SPL with the chemical selectivity of catalysis, thereby greatly increasing the chemical scope and complexity that can be achieved by SPL. ${ }^{1,12}$

This type of direct synthesis is of particular relevance to the lithography of materials that are otherwise difficult to process by other approaches, such as conducting polymers. For example, polyaniline is a conjugated polymer that exhibits high electrical conductivity and electrochemical stability, and is therefore of interest in the development of organic electronic devices. ${ }^{13-15}$ However, polyaniline has very low solubility in organic solvents and its decomposition temperature is below its glass transition temperature, making the practical manipulation of this material challenging. ${ }^{14,16}$ Methods for the generation of polyaniline features, to any user-defined design template, would therefore be highly desirable. ${ }^{15}$

As an exemplification of this strategy, the use of a biocatalytically functionalized scanning probes to perform the additive this report demonstrates lithography of polyanilines, by oxidative cross-coupling of anilines. Here, a recombinant horseradish peroxidase (HRP) is employed, which has been engineered to enable its use in an SPL context. This biocatalyst is particularly suitable for this application as it has a high redox potential (i.e. it is able to catalyze oxidations of otherwise stable aromatic substrates), uses $\mathrm{H}_{2} \mathrm{O}_{2}$ as a terminal oxidant that is safe and readily available, operates under mild ambient conditions, and has previously been shown to catalyze oxidations when placed at the tip of an AFM probe. ${ }^{17}$ Furthermore, parallelization of this biocatalytic SPL over large $\left(\mathrm{cm}^{2}\right)$ areas using an array of elastomeric 
probes (c.f. polymer pen lithography), ${ }^{18}$ and the postlithographic derivatization of the polyaniline features, are also demonstrated.

\section{Results and Discussion}

\section{Biocatalytic probe array preparation.}

In order to realize the proposed biocatalytic nanolithography, a number of considerations needed to be addressed. Firstly, in order for the nanolithography to be precise (i.e. only at the point of contact between the probes and the surface) it was necessary to confine the enzymes to the apex of each probe. ${ }^{17}$ Since each probe tip would therefore only carry a relatively small number of enzyme molecules, it was also necessary to employ a site-specific method of protein immobilization that gives a uniform protein orientation relative to the probes, and thus achieve maximum activity from each protein. For this purpose, the HRP was recombinantly engineered so that it was fused to a ybbR tag, which can be immobilized onto coenzyme A-functionalized materials by the phosphopantetheinyl transferase enzyme Sfp. ${ }^{1,19}$ Taking these issues into consideration, the elastomeric probe arrays with HRP confined to the tip apex were constructed and employed following the workflow shown in Scheme 1.

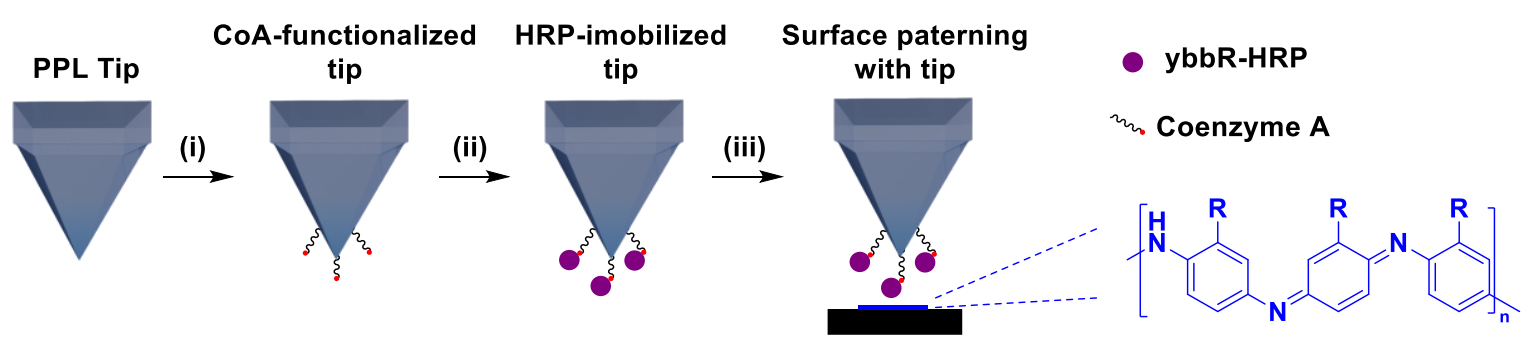

Scheme 1. Workflow for the functionalization of the scanning probes and their use in the nanolithography of polyaniline features. Steps: (i) functionalization of PDMS tips with coenzyme A (see also scheme 2a); (ii) site-selective immobilization of ybbR-HRP mediated by Sfp (see scheme 2b); (iii) biocatalytic nanolithography of polyaniline features. 
Polydimethylsiloxane (PDMS) elastomeric probe arrays of the type typically used for $\mathrm{PPL}^{20}$ were used as the basis of the biocatalytic probe array. In all cases arrays of $1 \times 1 \mathrm{~cm}^{2}$ were used. The array was first amino-functionalized by vapor deposition of 3aminopropyltriethoxysilane $\mathbf{1}$, followed by the attachment of an oligoethylene glycol linker with a terminal maleimide group 2 (Scheme 2a). Any unreacted amines were blocked by treatment with acetic anhydride. The array was mounted on an AFM, which was used to precisely bring the probe into contact with a silicon substrate drop-coated with coenzyme A, thus ensuring that only the tips of the probes would be ligated with the coenzyme required for subsequent protein immobilization. The remaining unreacted maleimide groups, which coated the entire surface of the array, were blocked by immersion in a solution of 2mercaptoethanol. Following washing to remove any unreacted reagents, the arrays were finally submerged in a solution containing Sfp and ybbR-HRP to allow enzyme conjugation (scheme $2 \mathrm{~b}$ ). Alignment of the probe array relative to the coenzyme A-bearing surface, as well as controlling its contact to the surface was vital to ensure the uniformity of protein immobilization and subsequent lithography performance. It was found that excessive probesurface contact resulted in the lithography of overly large features, while lack of contact would result in no features being produced. 


\section{(a)}
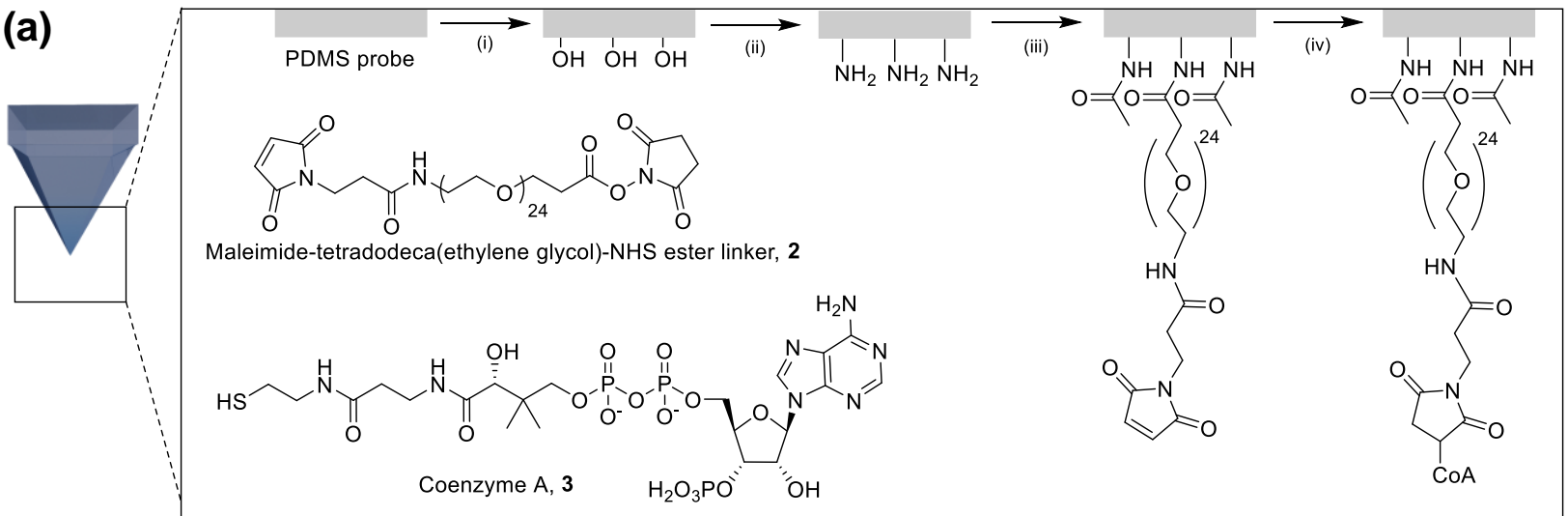

(b)
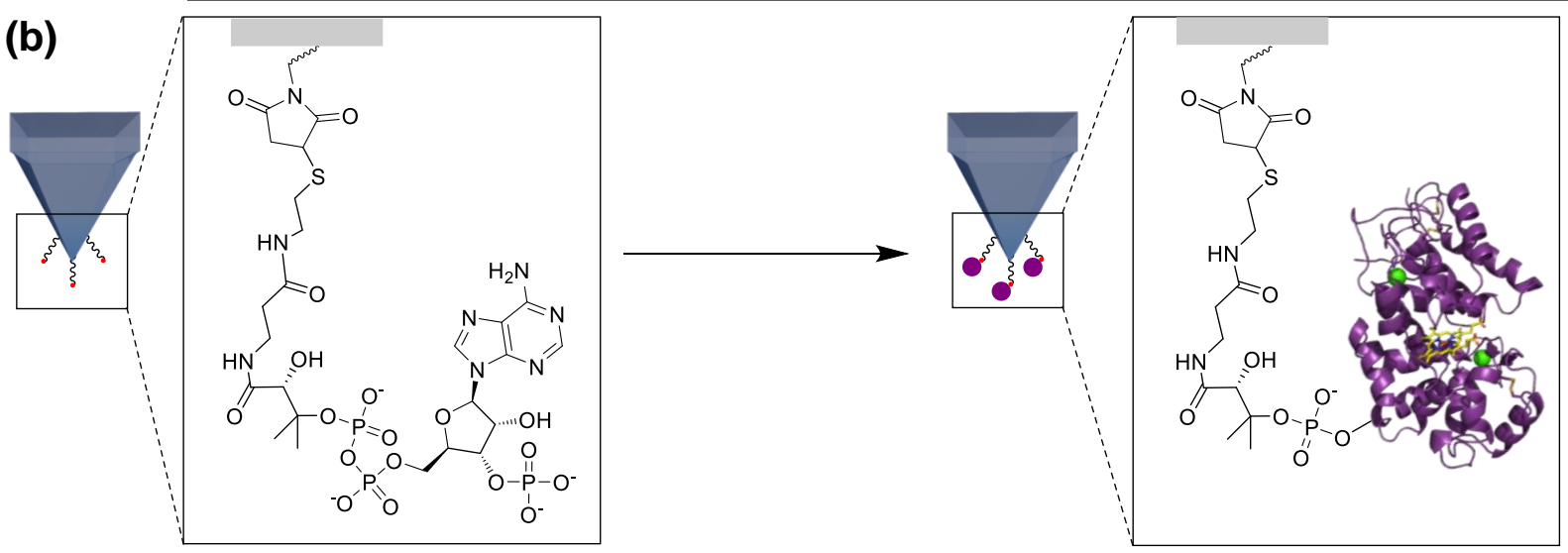

Scheme 2. (a) Coenzyme A functionalization onto the PDMS probes. Steps: (i) surface oxidation by oxygen plasma; (ii) vapor deposition of $\mathbf{1}$ followed by thermal curing; (iii) ligation of $\mathbf{2}$, then blocking of unreacted amines with acetic anhydride; (iv) ligation of $\mathbf{3}$ then blocking of unreacted maleimides with 2-mercapotethanol. (b) Site-specific ybbR-HRP immobilization catalyzed by the transferase enzyme Sfp.

The peroxidase activity of HRP immobilized on the probes was confirmed with a colorimetric assay using 2,2'-azino-bis(3-ethylbenzothiazoline-6-sulphonic acid) (ABTS) and $\mathrm{H}_{2} \mathrm{O}_{2}{ }^{21}$ Thus, upon immersing the array into the assay solution, the immobilized HRP catalyzes the generation of a colored product, the intensity of which is monitored by UV-vis spectrometry at $405 \mathrm{~nm}$ (Figure S1 in SI). For comparison, the assay was also performed on arrays entirely coated with HRP, rather than only at the apices, as a positive control. Negative control experiments were conducted using unfunctionalized arrays, arrays where all 
maleimide groups were blocked with 2-mercaptoethanol prior to the protein immobilization, and arrays with full coenzyme A coverage where either Sfp or ybbR-HRP were omitted from the protein immobilization step (step ii in Scheme 1). Arrays with a full coverage of HRP show a rapid increase in absorbance, indicating the immobilization approach was effective. Those that were subject to the enzyme confinement only to the probe tips also showed an increase in activity, though it was lower compared to the fully coated arrays, as expected. In contrast, the negative controls gave essentially no activity.

\section{Lithography of poly(2-methoxyaniline) by enzyme-probe arrays.}

The HRP-functionalized probe arrays were then used to demonstrate the lithography of polymer features by biocatalytic polymerization of 2-methoxyaniline onto a silicon dioxide surface. Here, the surface was functionalized with 4-aminophenol that served as the site of attachment and subsequent growth of the polymer chains (Scheme 3). 2-methoxyaniline was chosen as a model enzyme substrate because the methoxy group provided a readily detectable signal by Raman spectroscopic imaging (see below). The lithography setup consisted of the HRP-bearing probes and silicon surface being placed in a fluid cell, with a solution of 2methoxyaniline and $\mathrm{H}_{2} \mathrm{O}_{2}$ being added upon the initiation of the lithography; followed by rapid retraction of the catalytic probes upon completion of the lithography. 


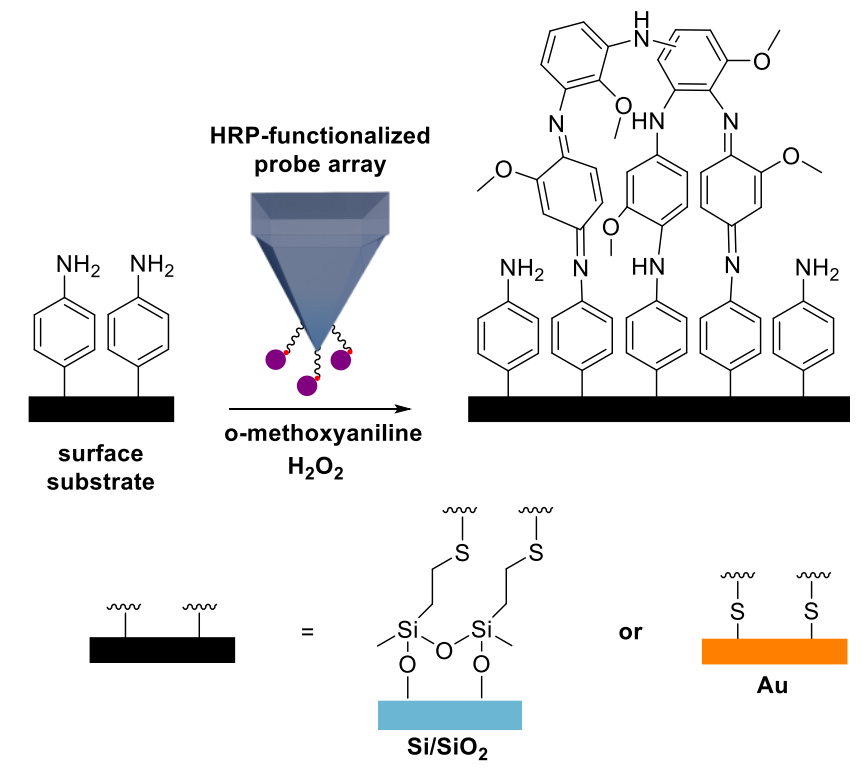

Scheme 3. Illustration of the HRP-catalyzed polymerization of 2-methoxyaniline reaction on aniline-functionalized silicon oxide or gold surfaces to form lithographic patterns.

As an example, lithography was performed such that each probe in the array patterned a series of lines composed of either 80 or 160 individual dot features, with a dwell time of 2 or $1 \mathrm{~s}$ per dot feature. AFM analysis post-lithography clearly showed topographic features that were consistent with the desired pattern (Figures 1a and b). Measurements taken across the line features in 20 representative locations across the printed area gave an average feature size of $489 \pm 52 \mathrm{~nm}$ (full width at half maximum height, fwhm) and an average height of 1.9 $\pm 1.1 \mathrm{~nm}$ (Figure $\mathrm{S} 2$ in SI). Further optimization enabled these features to be reduced to an fwhm of $162 \pm 24 \mathrm{~nm}$, with a similar height $(2.1 \pm 0.9 \mathrm{~nm}$, Figures $1 \mathrm{c}$ and d, Figure S3 in SI). 

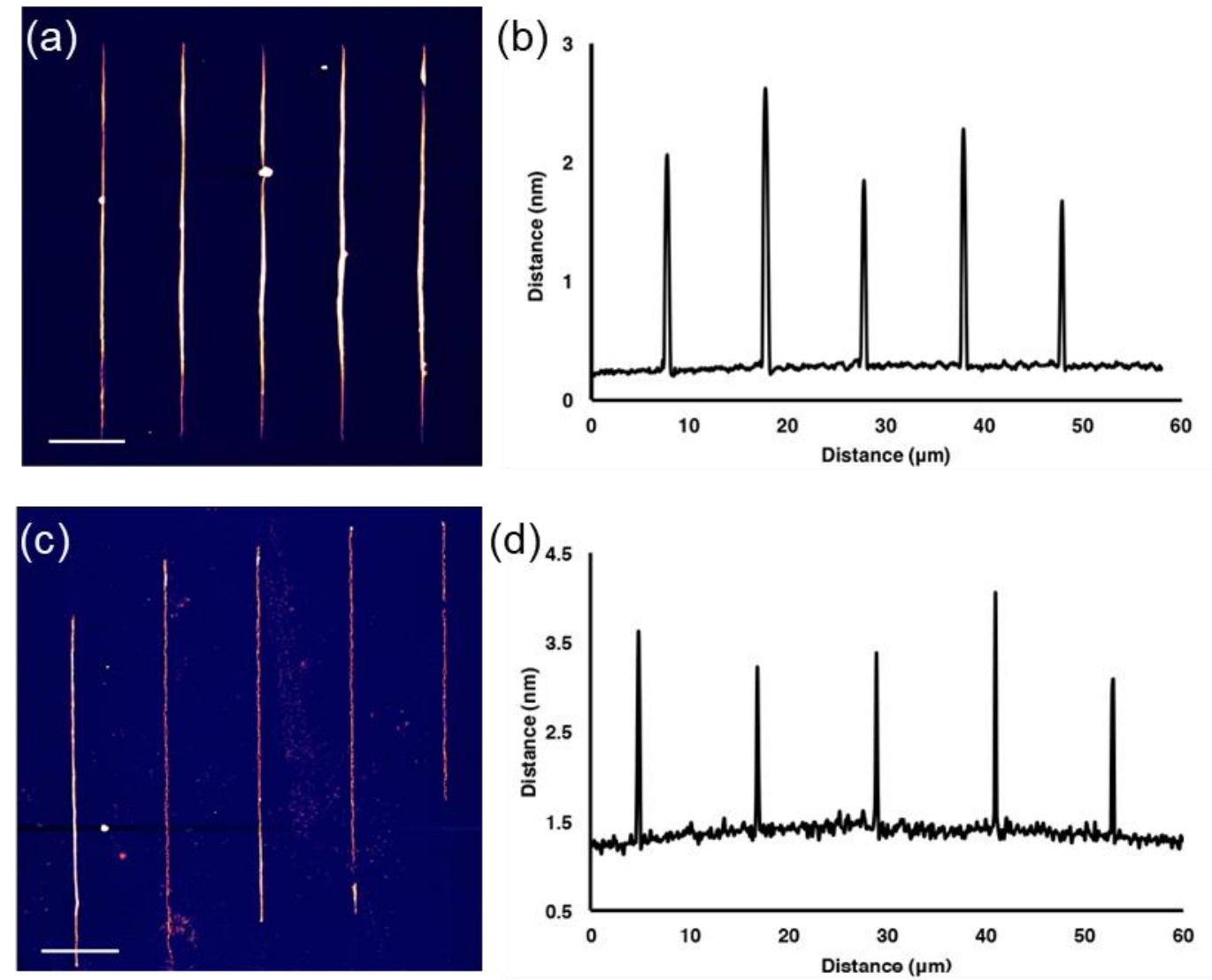

Figure 1. Illustrative AFM topographic images of poly(2-methoxyaniline) features and graphs of height against distance for representative cross-sections. (a and b) A series of parallel lines produced with $2 \mathrm{~s}$ dwell time per dot feature, 80 dot features per line, $2.6 \mathrm{mM} 2-$ methoxyaniline and $1 \mathrm{mM} \mathrm{H}_{2} \mathrm{O}_{2}$. (c and d) A series of diagonal lines produced with $1 \mathrm{~s}$ dwell time per dot feature, 160 features per line, $2.6 \mathrm{mM}$ 2-methoxyaniline and $1 \mathrm{mM} \mathrm{H}_{2} \mathrm{O}_{2}$. The scale bars in the images represent $10 \mu \mathrm{m}$.

These results compare favorably with the additive lithography of conducting polymers by DPN. For example, the deposition of proprietary formulations of pre-synthesized sulfonated polyaniline or polypyrrole colloids on to a polyamine surface gave lines that were 310 or $290 \mathrm{~nm}$, respectively. ${ }^{22}$ In another report, an approach whereby 4 -aminothiophenol was first deposited by DPN on a gold surface, followed by exposure of the patterned surface to a solution of $\mathrm{HRP}$ and $\mathrm{H}_{2} \mathrm{O}_{2}$, gave features with a width of $210 \mathrm{~nm} \cdot{ }^{23}$ It also compares 
favorably to a nanopipette method that used local electropolymerisation of 3,4ethylenedioxylthiophene or aniline, which gave features of $\sim 600 \mathrm{~nm} .{ }^{24}$ However, the reported features are larger than those achieved by "field assisted nanopatterning", whereby an AFM probe coated with pre-synthesized polyaniline can be made to deposit the polymer by applying an electrical bias between the probe and the conducting surface. ${ }^{25}$ This approach gave polyaniline features as small as $20 \mathrm{~nm}$, but can only be used with probes and surfaces that are electrically conductive. In all these cases, only lithography with a single probe was reported.

The typical apex width of the elastomeric probes $^{20}$ are approximately $60 \mathrm{~nm}$ and the oligoethylene linker is approximately $10 \mathrm{~nm}$ in length when fully extended, which implies that the theoretical maximum distance that can be reached by the tethered HRP molecule would encompass a diameter of $\sim 80 \mathrm{~nm}$. However, since the radical monomers that are generated must leave the enzyme active site prior to polymerization, it is postulated that the observed feature sizes are thus related to the distance these radicals can diffuse prior to deposition.

\section{Raman mapping on gold 4-aminothiophenol functionalized surfaces.}

In order to demonstrate the applicability of this lithographic approach to another substrate, the biocatalytic lithography was conducted in an analogous manner onto a self-assembled monolayer of 4-aminothiophenol on a gold surface. Since such metal substrates exhibit surface-enhanced Raman scattering (SERS), ${ }^{26-29}$ this experiment also enabled direct chemical detection and identification of the features by Raman spectroscopy.

Raman microscopy imaging was performed over an area of $100 \times 100 \mu \mathrm{m}$ with a spectra collected in a $200 \times 200$ grid (i.e. every $0.5 \mu \mathrm{m}$ apart). A plot of the signal intensity at $1398 \mathrm{~cm}^{-1}$, which corresponds to the quinoid C-N $\mathrm{N}^{+}$Raman band, shows strong signals 
corresponding to the pattern programmed into the instrumentation (Figure $2 \mathrm{a}$ and $\mathrm{b}$ ). In contrast, the unpatterned areas show no corresponding signal. The representative spectrum for the patterned area (Figure 2c, Table S1 in SI) was essentially identical to that of poly(2methoxyaniline) synthesized in solution by the conventional route. ${ }^{30}$ Indeed, the spectrum from the features displayed a peak at $1140 \mathrm{~cm}^{-1}$ corresponding to a $\mathrm{C}-\mathrm{O}$ bond vibration, which was attributed to the methoxy groups of the polymer. Its presence therefore indicated that the features arose from the polymerization of the methoxyaniline monomers, and not simply the oxidative crosslinking of the underlying aminothiophenol monolayer. In comparison, the spectrum for the unpatterned area is identical to that of a control surface consisting of only the 4-aminothiophenol monolayer (Figure 2d). 

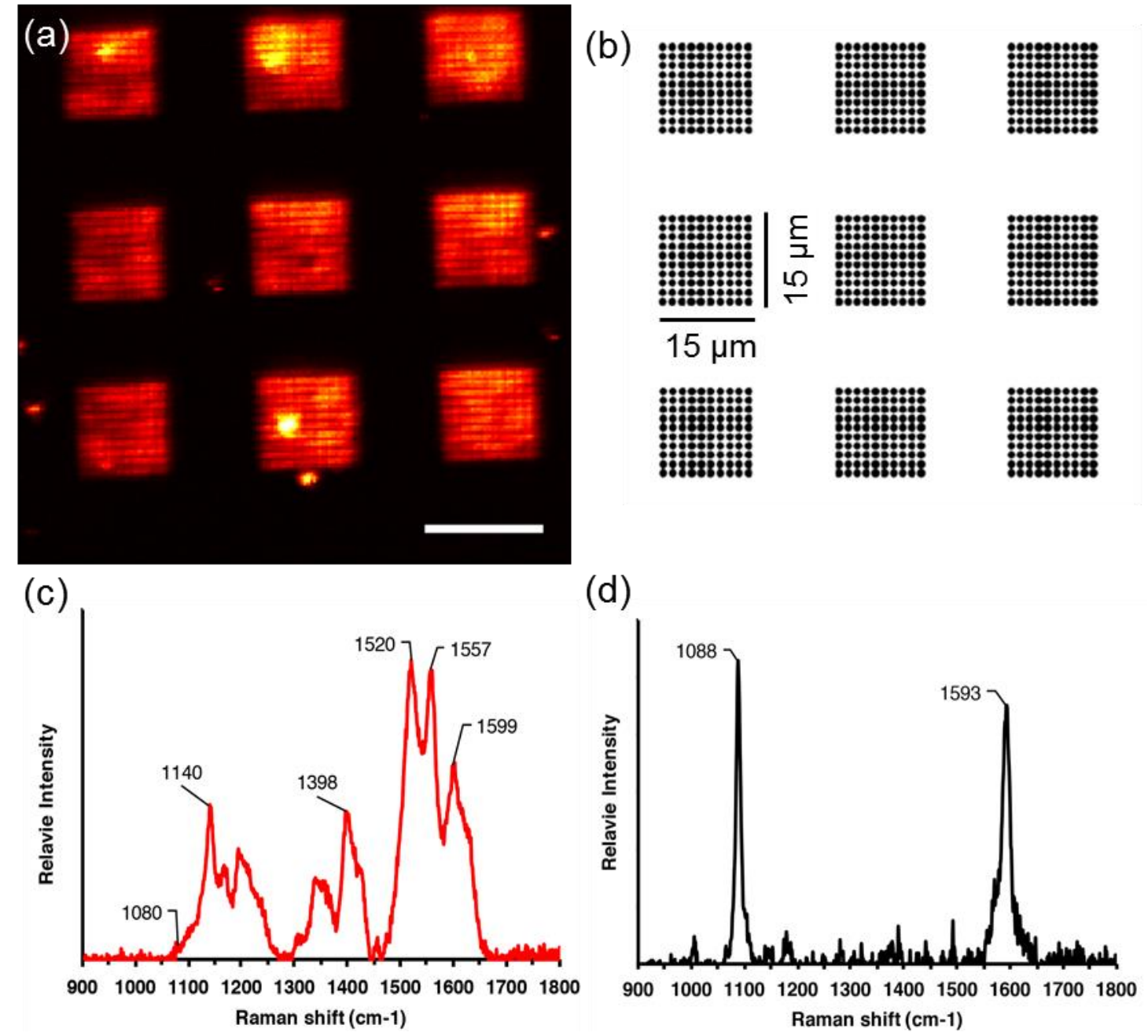

Figure 2. Raman chemical imaging of poly-2-methoxyaniline patterns obtained by HRPcatalyzed nanolithography on 4-aminothiophenol functionalized gold surfaces. (a) Raman microscopy map of signal intensity at $1398 \mathrm{~cm}^{-1}$ and (b) the template image used for lithography. Representative Raman spectra of: (c) the patterned area and (d) the unpatterned surface. The scale bar in the microscopy image represents $20 \mu \mathrm{m}$.

\section{Postlithography derivatization of polymer features.}

In order to demonstrate that the deposited polyaniline can be further chemically derivatized, and as a means to assess the wide-area nature of the parallelized lithography, an experiment to fluorescently tag the polymer patterns after the lithography was performed. Here, the Huisgen 1,3-dipolar "click" cycloaddition between an azide and alkyne was used as a 
convenient means for ligating the tags. ${ }^{31,32}$ For this purpose, 3-(prop-2-yn-1-yloxy)aniline was synthesized for use as the monomer in the biocatalytic lithography, which was then carried out in the same way as before. The patterned substrate was then submerged in a solution of azide-functionalized Alexafluor 488 in the presence of a $\mathrm{Cu}(\mathrm{I})$ catalyst to affect the click ligation. Subsequently, the surfaces were washed and imaged under a fluorescence microscope, where fluorescent features were observed that conformed to the patterns used (Figure 3); confirming successful parallelized lithography and post-lithographic derivatization. 

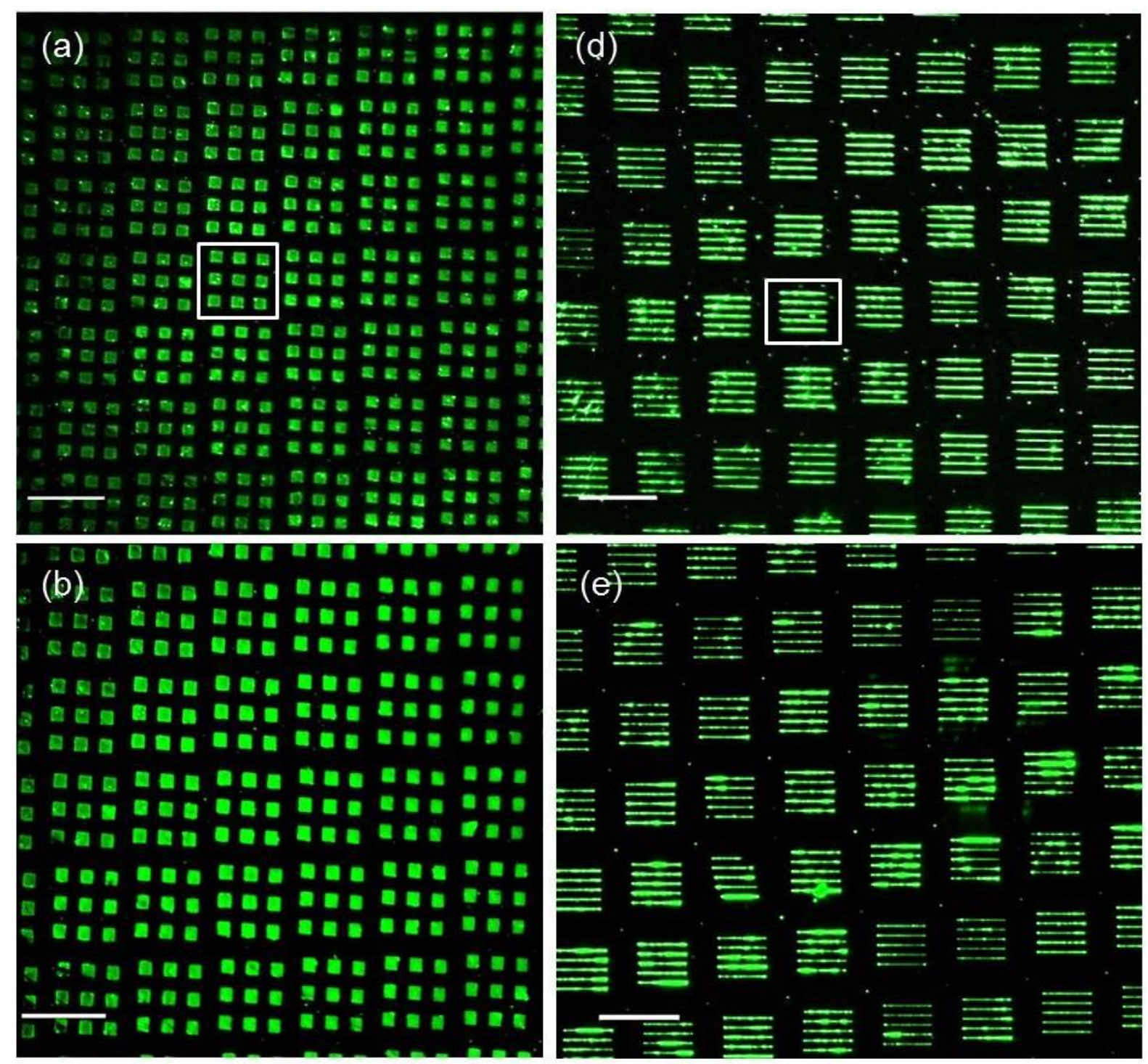

(c)
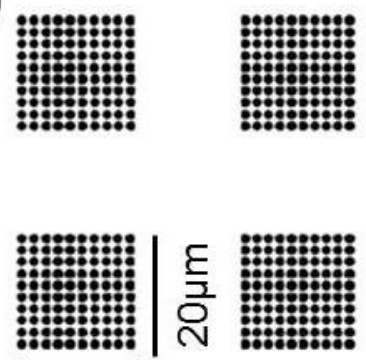

$\overline{20 \mu \mathrm{m}}$
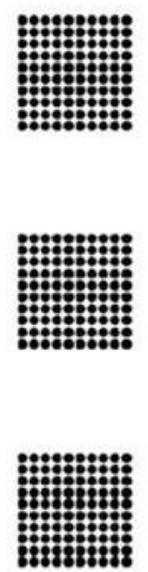
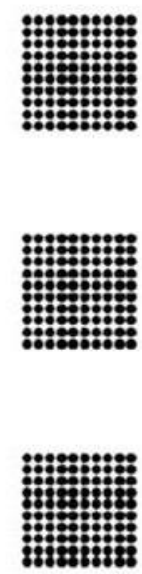

(f)

$50 \mu \mathrm{m}$

Figure 3. Epifluorescence microscopy images collected by excitation at $488 \mathrm{~nm}$ of the features after post-polymerization functionalization: ( $a$ and $b$ ) Illustrative images taken from different areas of the surface, where each probe generated an array of $10 \times 10$ dots in $3 \times 3$ 
grids (the white box indicating the pattern written by a single probe); (c) the template pattern written by a single probe; ( $\mathrm{d}$ and e) Illustrative images taken from different areas of the surface where each probe generated a series of 5 lines, each line is $50 \mu \mathrm{m}$ in length and generated from 50 dot features each (the white box indicating the pattern written by a single probe); (c) the template pattern written by a single probe. Scale bars on the microscopy images represent $100 \mu \mathrm{m}$.

\section{Conclusions}

Overall, this report demonstrates the feasibility of parallelized constructive biocatalytic nanolithography of conjugated polyaniline on both silicon dioxide and gold surfaces, over wide areas $\left(\mathrm{cm}^{2}\right)$ and under ambient conditions. The polyanilines were catalytically formed and deposited at high resolution, with feature widths of $162 \pm 24 \mathrm{~nm}$. These patterns were chemically analyzed by Raman microscopy, which confirmed that aniline polymers were being formed from the corresponding monomer feedstocks. Wide area patterning was further confirmed by modifying the deposited aniline polymers with a fluorescent moiety, which could then be imaged by wide-field fluorescence microscopy.

From a practical perspective, since a single round of enzyme production yielded sufficient ybbR-HRP for $\sim 50$ arrays, and PDMS is very inexpensive, these probe arrays can be treated as single-use "disposable" items. This approach thus ensures no crosscontamination of monomers between different rounds of lithography and maximally active enzymes are used on each occasion. One possible route to improve the resolution of the reported method would be to use arrays of probes made from hard materials which would give sharper probe tips, such as those reported in hard-tip, soft-spring lithography. ${ }^{18}$ 
In comparison with previous attempts at enzymatically-catalyzed nanolithography that only utilized serial (single probe) lithography, ${ }^{1}$ these patterns were of higher chemical complexity while giving superior resolution over larger areas. The generation of features consisting of conjugated polymers is of particular interest since these materials can be made to be electrically conducting, with potential applications in flexible electronic devices. ${ }^{13}$ While there are several SPL examples involving conjugated polymers, none show large-area parallelization, despite its potential usefulness in the fabrication of devices containing such materials.

Key to the success of this approach was the implementation of covalent and site specific protein immobilization, using a homogeneous and highly active enzyme preparation. Indeed, the approach described here is generally applicable to other enzymatic reactions, which would further widen the scope of biocatalytic nanolithography. Indeed, with the increasing availability of convenient tools for the genetic engineering of proteins, ${ }^{33,}{ }^{34}$ it is now possible to rationally design proteins specifically for use in conjunction with scanning probes. Such developments would be a possible route to incorporating biological catalysis in any future universal "desk-top fab" system.

\section{Experimental}

\section{Materials and Equipment.}

The maleimide linker 1 (MAL-dPEG $24-\mathrm{NHS}$ ester) was purchased from Quanta Biodesign (Plain City, $\mathrm{OH}$ ) and Azide-fluor 488 from Sigma-Aldrich (Poole, UK). The 2naphthylhydroxamic acid-functionalized agarose used for the protein purification was prepared according to procedures adapted from previous reports. ${ }^{35}$ The phosphopantetheinyl transferase Sfp was produced heterologously in E. coli and purified by metal affinity 
chromatography according to previously reported procedures. ${ }^{19}$ Gold substrates and silicon wafers were purchased from Sigma-Aldrich, and atomically flat glass microarray slides (Arrayit Superclean 2) from Arrayit (Sunnyvale, CA). All other reagents were purchased from the usual laboratory suppliers.

The lithography was performed on a custom-built AFM (Nanosurf AG, Liestal, Switzerland) equipped with the automated alignment algorithm reported elsewhere. ${ }^{36}$ Raman microscopy was performed on a Renishaw inVia confocal Raman microscope using a 532nm laser source. Epifluorescence microscopy was carried out with a Fluorescent Stereo Microscope, (Leica Microsystems GmbH, Germany).

\section{Production of ybbR-HRP.}

The C1A isoform of HRP was used for this work, ${ }^{37}$ which was cloned into a pET28a plasmid vector using standard procedures to give a protein fused to an $\mathrm{N}$-terminal hexahistidine tag, followed by the ybbR tag. This protein was heterologously produced using standard methods in E. coli. Briefly, the plasmid was transformed into E. coli BL21(DE3). Cells were grown to an optical density of $0.6 \mathrm{OD}_{600}$, then gene expression was induced by the addition of $\beta$-D-1thiogalactopyranoside $(0.1 \mathrm{mM})$ at $37{ }^{\circ} \mathrm{C}$ for $3 \mathrm{~h}$, after which the cells were collected by centrifugation (4000 $\mathrm{g}$ for $15 \mathrm{~min}$ ) and the supernatant removed.

These cells were resuspended in $50 \mathrm{mM}$ Tris buffer $\mathrm{pH} 8$ containing $1 \mathrm{mM}$ EDTA and $10 \mathrm{mM}$ DTT (buffer A); and left to stand for $1 \mathrm{~h}$ at $4{ }^{\circ} \mathrm{C}$ prior to lysis by sonication $(5 \times 30 \mathrm{~s})$. The lysate was separated by centrifugation ( $8000 \mathrm{~g}$ for $40 \mathrm{~min}$ ) and the supernatant discarded. The pellet was thoroughly resuspended in $50 \mathrm{mM}$ Tris buffer $\mathrm{pH} 8$ containing $2 \mathrm{M}$ urea (buffer B), subjected to centrifugation (8000 g for $40 \mathrm{~min}$ ) and supernatant discarded. The pellet containing washed inclusion bodies were finally solubilized in $50 \mathrm{mM}$ Tris buffer $\mathrm{pH} 8$ containing $1 \mathrm{mM}$ DTT and $6 \mathrm{M}$ urea (buffer C), and subjected to centrifugation (8000 $\mathrm{g}$ for 
$40 \mathrm{~min}$ ). The supernatant, now containing the solubilized inclusion bodies, was then purified by Ni-affinity chromatography under denaturing conditions in Buffer $\mathrm{C}$ containing increasing concentrations of imidazole. The purified denatured protein (final concentration approximately $0.18 \mathrm{mg} / \mathrm{mL}$ ) was then added drop-wise to the refolding buffer (1.7 $\mathrm{M}$ urea, 2 $\mathrm{mM} \mathrm{CaCl} 2,7 \%$ glycerol, $0.35 \mathrm{mM}$ oxidized glutathione, $0.044 \mathrm{mM}$ dithiothreitol) and stirred at $4{ }^{\circ} \mathrm{C}$ for $16 \mathrm{~h} .{ }^{38}$ The solution was then filtered $(0.2 \mu \mathrm{m}$ pore size $)$ and purified by Ni-affinity chromatography to remove any aggregated protein. Refolded apoprotein was then reconstituted with heme by drop wise addition of hemin (from a $1 \mathrm{mM}$ solution of hemin in $20 \mathrm{mM} \mathrm{NaOH})$.

The reconstituted holoprotein was then buffer exchanged by centrifugal filtration into $50 \mathrm{mM}$ pH 5.5 succinate buffer. This material was then further purified by chromatography through 2-naphthylhydroxamic acid-functionalized agarose column, at a flow rate of $1 \mathrm{~mL}$ $\min ^{-1}$, by elution with $50 \mathrm{mM}$ succinate and $200 \mathrm{mM}$ sodium borate buffer at $\mathrm{pH}$ 5.5. The pure protein was then buffer exchanged into $25 \mathrm{mM}$ Tris $50 \mathrm{mM} \mathrm{NaCl} \mathrm{pH} 7.5$ and

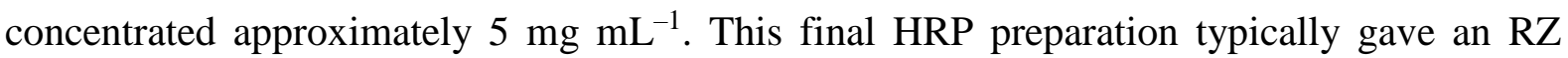
$\left(\mathrm{A}_{404} / \mathrm{A}_{280}\right)$ ratio of 2.93 .

\section{Synthesis of 3-(Prop-2-yn-1-yloxy)aniline..$^{39-41}$}

3-nitrophenol (2.75 $\mathrm{g}, 20 \mathrm{mmol})$ was dissolved in diethyl ether $(20 \mathrm{~mL})$ and potassium carbonate $(3.17 \mathrm{~g}, 23 \mathrm{mmol})$ was added. The mixture was stirred for $10 \mathrm{~min}$, after which propargyl bromide $(2.5 \mathrm{~mL}, 22 \mathrm{mmol})$ was added and the mixture refluxed for $5 \mathrm{~h}$. Subsequently, the reaction was cooled to room temperature and the organic phase was washed with water $(2 \times 20 \mathrm{~mL})$, brine $(2 \times 10 \mathrm{~mL})$ and saturated potassium carbonate solution $(20 \mathrm{~mL})$. The organic phase was then dried over anhydrous magnesium sulfate, 
filtered and the solvent removed under reduced pressure to yield 1-nitro-3-(prop-2-yn-1yloxy)benzene (2.409 $\mathrm{g}, 13.6 \mathrm{mmol}, 69 \%)$ as an orange solid.

The 1-nitro-3-(prop-2-yn-1-yloxy)benzene (147 mg, $0.83 \mathrm{mmol}$ ) and iron powder (279 $\mathrm{mg}, 5.00 \mathrm{mmol})$ were suspended in a solution of glacial acetic acid ( $2 \mathrm{~mL})$, ethanol (2 $\mathrm{mL})$ and water $(1 \mathrm{~mL})$. The resulting suspension was ultrasonically agitated at $30{ }^{\circ} \mathrm{C}$ until the reaction was observed to be complete (by TLC, typically $2 \mathrm{~h}$ ). The solution was filtered and the residue washed with ethyl acetate $(30 \mathrm{~mL})$. The combined filtrate and washings were extracted with potassium hydroxide $(2 \mathrm{M}, 20 \mathrm{~mL})$, and this aqueous phase extracted with diethyl ether $(2 \times 25 \mathrm{~mL})$. The combined organic phases were washed with brine $(2 \times 25 \mathrm{~mL})$, followed by water $(3 \times 50 \mathrm{~mL})$, dried over anhydrous magnesium sulfate, filtered and the solvent removed under reduced pressure. The residue was subjected to flash column chromatography $\left(\mathrm{SiO}_{2}\right.$, hexane: ethyl acetate; 2:1) to yield the desired 3-(prop-2-yn-1yloxy)aniline (57 mg, $0.39 \mathrm{mmol}, 47 \%$ ) as a yellow oil. Rf: 0.41 (hexane: ethyl acetate; 2:1), ${ }^{1} \mathrm{H}$ NMR $\left(400 \mathrm{MHz}, \mathrm{CDCl}_{3}\right) \delta 7.07(\mathrm{t}, \mathrm{J}=8.0 \mathrm{~Hz}, 1 \mathrm{H}), 6.39(\mathrm{ddd}, \mathrm{J}=8.2,2.4,0.7 \mathrm{~Hz}, 1 \mathrm{H})$, $6.33(\mathrm{ddd}, \mathrm{J}=7.9,2.1,0.8 \mathrm{~Hz}, 1 \mathrm{H}), 6.30(\mathrm{t}, \mathrm{J}=2.2 \mathrm{~Hz}, 1 \mathrm{H}), 4.64(\mathrm{~d}, \mathrm{~J}=2.4 \mathrm{~Hz}, 2 \mathrm{H}), 3.65(\mathrm{~s}$, 2H), $2.53(\mathrm{t}, \mathrm{J}=2.4 \mathrm{~Hz}, 1 \mathrm{H}) ;{ }^{13} \mathrm{C} \mathrm{NMR}\left(101 \mathrm{MHz}, \mathrm{CDCl}_{3}\right) \delta 158.77,147.89,130.16,108.81$, 104.70, 102.04, 78.89, 75.44, 55.70; m/z $\left(\mathrm{ESI}^{+}\right) 148.1\left(100 \%,[\mathrm{M}+\mathrm{H}]^{+}\right)$, HRMS found 148.0754; $\mathrm{C}_{9} \mathrm{H}_{10} \mathrm{NO}^{+}$requires 148.0760.

\section{Synthesis of Tert-butyl(4-mercaptophenyl)carbamate. ${ }^{42}$}

To a stirred slurry of di-tert-butyl dicarbonate $(554 \mathrm{mg}, 2.5 \mathrm{mmol})$ and indium chloride (90 $\mathrm{mg}, 0.025 \mathrm{mmol}$ ), 4-aminobenzenethiol (313 $\mathrm{mg}, 2.5 \mathrm{mmol}$ ) was added and heated at $35{ }^{\circ} \mathrm{C}$. The reaction was monitored by TLC and was observed to be complete after $1 \mathrm{~h}$. The resulting reaction mixture was suspended in ethyl acetate $(25 \mathrm{~mL})$ and washed with water $(3 \times 25 \mathrm{~mL})$. The organic phase was dried over anhydrous magnesium sulfate, filtered and the solvent 
removed under reduced pressure. Flash column chromatography $\left(\mathrm{SiO}_{2}\right.$, hexane: ethyl acetate; 2:1) subsequently yielded tert-butyl (4-mercaptophenyl)carbamate (0.545 g, 2.4 mmol, 97\%) as a white solid. Rf: 0.36 (hexane: ethyl acetate; 2:1), Mp: 179-180 ${ }^{\circ}$. ${ }^{1} \mathrm{H}$ NMR $(400 \mathrm{MHz}$, $\left.\mathrm{CDCl}_{3}\right) \delta 7.39(\mathrm{~d}, \mathrm{~J}=8.7 \mathrm{~Hz}, 2 \mathrm{H}), 7.29(\mathrm{~d}, \mathrm{~J}=8.7 \mathrm{~Hz}, 2 \mathrm{H}), 6.48(\mathrm{~s}, 1 \mathrm{H}), 1.57(\mathrm{~s}, 1 \mathrm{H}), 1.51(\mathrm{~s}$, $9 \mathrm{H}) ;{ }^{13} \mathrm{C} \mathrm{NMR}\left(101 \mathrm{MHz}, \mathrm{CDCl}_{3}\right) \delta 152.60,138.53,131.14(2 \mathrm{C}), 130.96,119.05$ (2C), 81.02, $28.46(3 \mathrm{C}) ; \mathrm{m} / z\left(\mathrm{ESI}^{+}\right) 226.1\left(100 \%,[\mathrm{M}+\mathrm{H}]^{+}\right)$.

\section{Preparation of 4-Aminobenzenethiol-Functionalized Silicon Oxide Surfaces.}

The following procedure was performed in a glove bag. Microarray glass slides were treated with $\mathrm{O}_{2}$ plasma (200 mTorr) for $1 \mathrm{~min}$ immediately prior to use, and were then immersed in a freshly prepared $1 \% v / v$ solution of (3-iodopropyl)trimethoxysilane in anhydrous toluene under an argon atmosphere at $80{ }^{\circ} \mathrm{C}$ for $24 \mathrm{~h}$. The slides were then removed, washed by rinsing with anhydrous toluene $(3 \times 5 \mathrm{~mL})$, by sonication in anhydrous acetone for 1 minute, then further washed with a stream of acetone $(1 \mathrm{~min})$ and dried with a stream of nitrogen gas. Finally the surfaces were annealed at $130{ }^{\circ} \mathrm{C}$ for $10 \mathrm{~min}$.

These freshly prepared (3-iodopropyl)trimethoxysilane functionalized surfaces were immersed in a freshly prepared solution of tert-butyl (4-mercaptophenyl)carbamate $(50 \mathrm{mM}$ in anhydrous methanol) under an argon atmosphere at $60{ }^{\circ} \mathrm{C}$ for $96 \mathrm{~h}$. Subsequently, the surfaces were washed by submerging them in 2-propanol $(3 \times 15 \mathrm{~min})$, acetone $(3 \times 15 \mathrm{~min})$ and dried under a stream of nitrogen gas.

Tert-butyl (4-mercaptophenyl)carbamate terminated surfaces were then immersed in a solution hydrochloric acid (4 $\mathrm{M}$ in 1,4-dioxane) under an argon atmosphere at room temperature for $12 \mathrm{~h}$. The surfaces were then washed by immersion in 1,4-dioxane $(3 \times 15$ $\min )$, followed by acetone $(3 \times 15 \mathrm{~min})$ and dried with a stream of nitrogen gas. The prepared surfaces were kept under vacuum and used within 2 weeks of preparation. 


\section{Preparation of 4-Aminobenzenethiol-Functionalized Gold Surfaces.}

Gold substrates $(10 \mathrm{~nm}$ gold with $2 \mathrm{~nm}$ titanium adhesion layer on aluminasilicate glass microscope slides) were immersed in a freshly prepared $5 \mathrm{mM}$ solution of 4-aminothiophenol in ethanol under an argon atmosphere for $96 \mathrm{~h}$ at room temperature. The surfaces were then washed by immersing them in ethanol $(3 \times 5 \mathrm{~min})$, sonication in ethanol for $1 \mathrm{~min}$, further rinsed with a stream of ethanol (1 min) and dried with a stream of nitrogen. These monolayer coated surfaces were kept under vacuum and used within 2 weeks of preparation.

\section{Ligation of Maleimido-Linker 1 onto PDMS Probe Arrays.}

PDMS probe arrays (50 $\mu \mathrm{m}$ or $100 \mu \mathrm{m}$ pitch), prepared according to previously reported procedures, were freshly peeled off the master and treated with $\mathrm{O}_{2}$ plasma for $30 \mathrm{~s}$ at 200 mTorr. ${ }^{36}$ The plasma-treated arrays and an empty glass vial were immediately placed inside a desiccator under an argon atmosphere and $100 \mu \mathrm{L}$ of (3-aminopropyl)triethoxysilane added to the vial. The desiccator was evacuated to 2-3 Torr and left to stand overnight at room temperature. The surfaces were then removed and cured at $110^{\circ} \mathrm{C}$ for $10 \mathrm{~min}$, before washing by submerging them in DMSO $(3 \times 5 \mathrm{~min})$, rinsing with an ethanol stream and drying under a stream of nitrogen.

The amino-functionalized surfaces were then submerged in a $5 \mathrm{mM}$ solution of maleimide-linker 1 in DMSO for $2 \mathrm{~h}$ at room temperature with gentle agitation, then washed, rinsed and dried as above.

\section{Ligation of Coenzyme A to Probe Apices.}

An $8 \mathrm{mM}$ coenzyme A trilithium salt aqueous solution was drop-coated on to half a silicon wafer (approximately $4 \times 2 \mathrm{~cm}$ ) and allowed to air dry. The maleimide-functionalized array 
was then aligned (using auto alignment software as previously described) ${ }^{36}$ to the uncoated half of the wafer surface. Upon completion of the alignment the stage was retracted on its zaxis and moved in its $\mathrm{y} / \mathrm{x}$-axis until the array was over the drop-coated area, and the humidity was set at $40 \%$. The stage was then moved in its z-axis until contact was observed (using minimum force or visual inspection). Contact was held for 5 min then the stage retracted in its $\mathrm{z}$-axis. The stage was moved diagonally on the $\mathrm{x} / \mathrm{y}$-axis by $10 \mu \mathrm{m}$ and this contacting process was repeated twice, following which the array was incubated at $60 \%$ humidity for 2 h. The array was then washed by submerging in water $(3 \times 5 \mathrm{~min})$ followed by an aqueous solution of $80 \mathrm{mM}$ 2-mecaptoethanol to block the remaining unreacted maleimide groups.

\section{ybbR-HRP Immobilization onto Probe Arrays.}

A reaction mixture consisting of $50 \mathrm{mM}$ sodium phosphate $\mathrm{pH} 7.4$ buffer, $10 \mathrm{mM} \mathrm{MgCl} \mathrm{Mg}_{2}, 5$ mM Sfp, $1 \mu \mathrm{M}$ TCEP, and $20 \mu \mathrm{M}$ ybbR-C1A was pipetted on to CoA-functionalized surfaces, incubated at $37{ }^{\circ} \mathrm{C}$ for $2 \mathrm{~h}$ at $100 \%$ relative humidity. The surfaces were then washed by submerging them in $50 \mathrm{mM}$ sodium phosphate buffer $\mathrm{pH} 7.4$, with $0.5 \%$ tween $(3 \times 15 \mathrm{~min})$, $50 \mathrm{mM}$ sodium phosphate buffer $\mathrm{pH} 7.4(3 \times 5 \mathrm{~min})$, and finally rinsing with $50 \mathrm{mM}$ sodium phosphate buffer $\mathrm{pH}$ 7.4. The arrays were stored in $50 \mathrm{mM}$ HEPES buffer at $\mathrm{pH} 7.4$ and used within one week. Surfaces were rinsed with water and dried with a stream of nitrogen prior to use in the lithography experiments.

\section{ABTS Peroxidase Activity Assays on Immobilized HRP.}

The probe arrays were attached inside individual wells in a 24 -well microtiter plate with double-sided tape. $500 \mu \mathrm{L}$ of assay solution $(50 \mathrm{mM}$ sodium acetate $\mathrm{pH} 4.5,0.77 \mathrm{mM}$ hydrogen peroxide, $1.00 \mathrm{mM}$ ABTS) added to each well, and the UV-vis absorbance at 405 
$\mathrm{nm}$ was read every $15 \mathrm{~s}$ with the plate swirled between each reading to ensure homogenous mixing of the solution.

\section{Lithography on 4-Aminothiophenol Surfaces.}

The array was then mounted onto the AFM scan head using double-sided tape and the substrate (functionalized silicon oxide or gold surfaces) was mounted at the bottom of a $1.5 \times$ $1.5 \times 0.5 \mathrm{~cm}$ fluid well on to the sample stage using double-sided tape. The fluid well then filled with a $2.6 \mathrm{mM}$ solution of enzyme substrate (2-methoxyanilne or 3-(prop-2-yn-1yloxy)aniline) in $50 \mathrm{mM}$ acetate buffer $\mathrm{pH} 5$ to submerge the surface (approximately $3 \mathrm{~mL}$ ). Alignment of the probe array relative to the surface was performed ${ }^{36}$ and the array was then retracted to above the level of fluid. Hydrogen peroxide added to a final concentration of 1 $\mathrm{mM}$ (final volume of solution typically $4 \mathrm{~mL}$ ). The array was then very rapidly brought within $10 \mu \mathrm{m}$ of the surface and patterning commenced with the predefined template to produce the desired pattern using the standard lithography software provided with the instrument, with each dot feature representing at a $2 \mathrm{~s}$ dwell time at that location. Patterning was undertaken at $60 \%$ relative humidity to prevent evaporation of the solution in the open fluid well.

Upon completion the array was immediately lifted from the solution and the enzymefunctionalised probe arrays discarded (i.e. not reused). The substrate was then removed and washed by immersion in $50 \mathrm{mM}$ acetate buffer $\mathrm{pH} 5(3 \times 5 \mathrm{~min})$ followed by $1 \mathrm{M}$ aq. $\mathrm{HCl}(3$ $\times 5 \mathrm{~min})$ and finally water $(3 \times 5 \mathrm{~min})$; dried under a stream of nitrogen and immediately imaged by AFM or Raman microscopy.

\section{Postlithographic Functionalization of Poly(3-(prop-2-yn-1-yloxy)aniline.}


The substrates bearing the polymer were submerged in an aqueous solution of $1 \mathrm{mM}$ Azidefluor 488 and $0.1 \mathrm{mM}$ copper(I) iodide in the dark for $24 \mathrm{~h}$ at room temperature. The surfaces were then washed by submersion in water $(6 \times 15 \mathrm{~min})$, dried under a stream of nitrogen and immediately visualized by epifluorescence microscopy with fluorescent excitation at $488 \mathrm{~nm}$.

\section{Conflicts of Interest.}

The authors declare no conflicts of interest.

\section{Acknowledgements}

Support is acknowledged from the Engineering and Physical Sciences Research Council (UK) under grants EP/K024485/1 and EP/K011685/1, as well as a graduate studentship to JH under grant EP/J50032X/1. Support is also acknowledged from the Biotechnology and Biological Sciences Research Council (UK) for support of the Raman microscopy equipment under grant BB/L014823/1 and a Doctoral Training Partnership studentship to MV under grant $\mathrm{BB} / \mathrm{J} 014478 / 1$.

\section{Footnotes.}

Time course plots of ABTS peroxidase activity assays with probe arrays, AFM topographic cross-sections of the polymer features, and a table of assignments for the Raman spectra of the polymers are provided in the supplementary information. 


\section{References}

1. S. A. Carnally and L. S. Wong, Nanoscale, 2014, 6, 4998.

2. R. Garcia, A. W. Knoll and E. Riedo, Nat. Nanotechnol., 2014, 9, 577.

3. S. Xu and G.-Y. Liu, Langmuir, 1997, 13, 127.

4. H. Sugihara, A. Takahara and T. Kajiyama, J. Vac. Sci. Technol. B., 2001, 19, 593.

5. J. N. Ngunjiri, D. J. Stark, T. Tian, K. A. Briggman and J. C. Garno, Anal. Bioanal. Chem., 2013, 405, 1985.

6. Y. Yan, Y. Geng and Z. Hu, Int. J. Mach. Tools Manuf., 2015, 99, 1.

7. H. C. Day and D. R. Allee, Appl. Phys. Lett., 1993, 62, 2691.

8. D. H. Lee, C. K. Kim, J.-H. Lee, H.-J. Chung and B. H. Park, Carbon, 2016, 96, 223.

9. W.-K. Lee, M. Haydell, J. T. Robinson, A. R. Laracuente, E. Cimpoiasu, W. P. King and P. E. Sheehan, ACS Nano., 2013, 7, 6219.

10. R. Garcia, R. V. Martinez and J. Martinez, Chem. Soc. Rev., 2006, 35, 29.

11. M. Ghatkesar, H. Garza, F. Heuck and U. Staufer, Micromachines, 2014, 5, 954.

12. V. Mesquita, J. Botton, D. A. Valyaev, C. François, L. Patrone, T. S. Balaban, M. Abel, J.-L. Parrain, O. Chuzel and S. Clair, Langmuir, 2016, 32, 4034.

13. T.-H. Le, Y. Kim and H. Yoon, Polymers, 2017, 9, 150.

14. S. Bhadra, D. Khastgir, N. K. Singha and J. H. Lee, Prog. Polym. Sci., 2009, 34, 783810.

15. L. Jiang, X. Wang and L. Chi, Small, 2011, 7, 1309-1321.

16. C. D. Liu, S. Y. Wu, J. L. Han and K. H. Hsieh, J. Appl. Polym. Sci., 2010, 115, 22712276.

17. X. Luo, V. A. Pedrosa and J. Wang, Chem. Eur. J., 2009, 15, 5191. 
18. L. R. Giam, A. J. Senesi, X. Liao, L. S. Wong, J. Chai, D. Eichelsdorfer, W. Shim, B. Rasin, S. He and C. A. Mirkin, Proc. SPIE, 2011, 8031, 803103.

19. L. S. Wong, J. Thirlway and J. Micklefield, J. Am. Chem. Soc., 2008, 130, 12456.

20. F. Huo, Z. Zheng, G. Zheng, L. R. Giam, H. Zhang and C. A. Mirkin, Science, 2008, 321, 1658.

21. H. Gallati, Clin. Chem. Lab. Med., 1979, 17, 1.

22. J. H. Lim and C. A. Mirkin, Adv. Mater., 2002, 14, 1474-1477.

23. P. Xu and D. L. Kaplan, Adv. Mater., 2004, 16, 628-633.

24. C. Laslau, D. E. Williams, B. Kannan and J. Travas-Sejdic, Adv. Funct. Mater., 2011, 21, 4607-4616.

25. J.-F. Liu and G. P. Miller, J. Phys. Chem. C, 2007, 111, 10758-10760.

26. P. A. Kilmartin and G. A. Wright, Synth. Met., 1999, 104, 145.

27. F. Flory, L. Escoubas and G. Berginc, J. Nanophoton., 2011, 5, 052502.

28. N. Tiwari, M. Y. Liu, S. Kulkarni and Y. Fang, J. Nanophoton., 2011, 5, 053513.

29. S. Mondal, U. Rana and S. Malik, ACS Appl. Mater. Interfaces, 2015, 7, 10457.

30. W. Liu, J. Kumar, S. Tripathy, K. J. Senecal and L. Samuelson, J. Am. Chem. Soc., 1999, 121, 71 .

31. V. V. Rostovtsev, L. G. Green, V. V. Fokin and K. B. Sharpless, Angew. Chem., 2002, 114, 2708.

32. J.-F. Lutz, Angew. Chem. Int. Ed., 2007, 46, 1018.

33. U. T. Bornscheuer, G. W. Huisman, R. J. Kazlauskas, S. Lutz, J. C. Moore and K. Robins, Nature, 2012, 485, 185.

34. N. J. Turner, Nat. Chem. Biol., 2009, 5, 567-573.

35. L. Reimann and G. R. Schonbaum, Methods Enzymol., 1978, 52, 514.

36. S. Wang, J. Hosford, W. P. Heath and L. S. Wong, RSC Adv., 2015, 5, 61402. 
37. F. W. Krainer, R. Pletzenauer, L. Rossetti, C. Herwig, A. Glieder and O. Spadiut, Protein Expr. Purif., 2014, 95, 104.

38. S. Asad, B. Dabirmanesh, N. Ghaemi, S. M. Etezad and K. Khajeh, Mol. Biotechnol., $2013, \mathbf{5 4}, 484$.

39. F. Liu, J. Liu and T. Zhao, J. Appl. Polym. Sci., 2010, 115, 3103.

40. B. K. Patel, H. Ghosh, A. Baneerjee and S. K. Rout, ARKIVOC, 2011, 2011, 209.

41. K.-C. Tiew, D. Dou, T. Teramoto, H. Lai, K. R. Alliston, G. H. Lushington, R. Padmanabhan and W. C. Groutas, Bioorg. Med. Chem., 2012, 20, 1213.

42. D. Niculescu-Duvaz, C. Gaulon, H. P. Dijkstra, I. Niculescu-Duvaz, A. Zambon, D. Ménard, B. M. J. M. Suijkerbuijk, A. Nourry, L. Davies, H. Manne, F. Friedlos, L. Ogilvie, D. Hedley, S. Whittaker, R. Kirk, A. Gill, R. D. Taylor, F. I. Raynaud, J. Moreno-Farre, R. Marais and C. J. Springer, J. Med. Chem., 2009, 52, 2255. 
Table of Contents Graphic
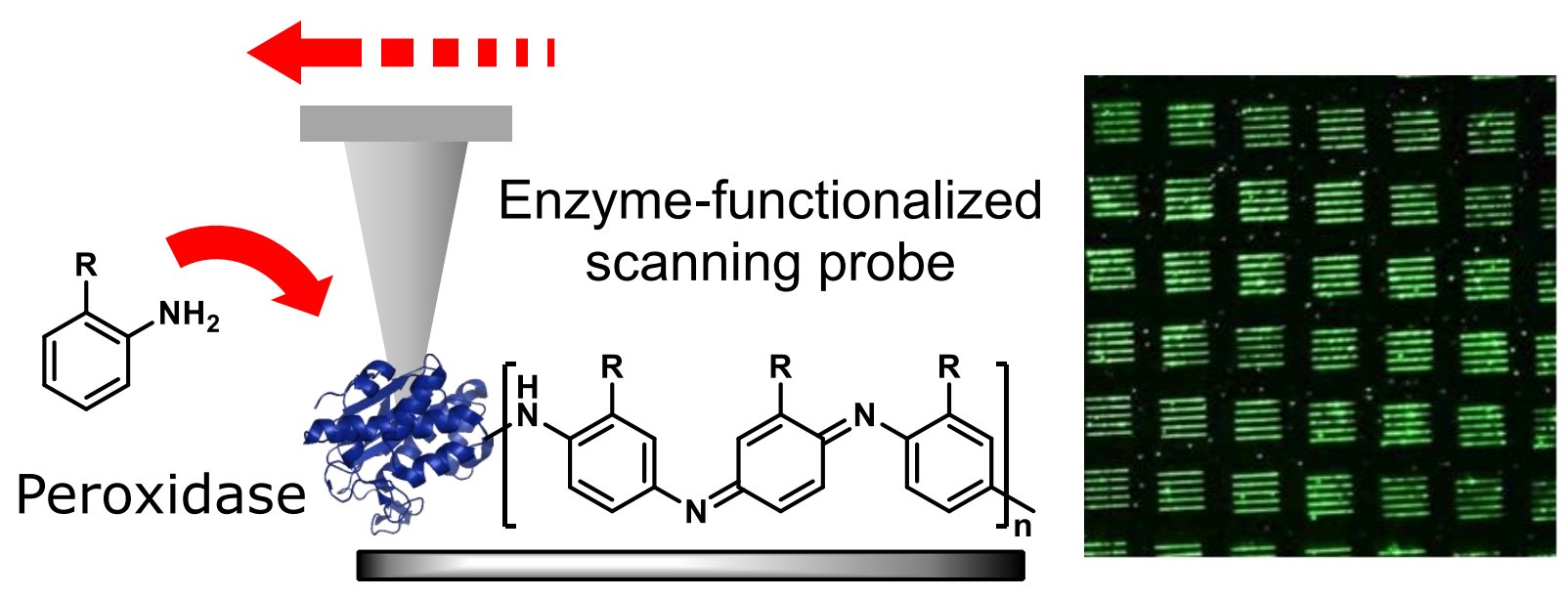